\title{
(TRANS)FORMAÇÃO DA PRÁTICA: \\ A EXPERIÊNCIA DE IMPLEMENTAÇÃO DA POLÍTICA NACIONAL DE SAÚDE INTEGRAL DA POPULAÇÃO LGBT EM UMA REGIONAL DE SAÚDE DO ESTADO DE PERNAMBUCO
}

\author{
Tereza Cristina Oliveira da Silva 1 \\ Elaine Alexandre da Silva ${ }^{2}$ \\ Jéssica Aparecida Sobrinho Silva ${ }^{3}$ \\ Ellem Najla Ferreira Rodrigues ${ }^{4}$ \\ Roberta Mendes Batista de Oliveira ${ }^{5}$ \\ Cicero Inacio Davi Pereira ${ }^{6}$
}

RESUMO: Este trabalho objetiva-se socializar uma vivência coletiva baseada em experiências práticas, com a finalidade de implementar uma Política de Saúde. Para tanto, foi utilizado como material base, somando as nossas discussões, a relatoria do I fórum de saúde LGBT da V GERES/PE. Consideramos que os profissionais que atuam na área de saúde, devem observar o que provoca o adoecimento dessa população, bem como as políticas públicas que facilitam o acesso ao SUS.

Palavras-Chave: Políticas Públicas. Assistência Integral Saúde. Movimento LGBT.

ABSTRACT: This work aims to socialize a collective observation based on practical experiences, with the objective of implementing a Health Policy. For this purpose, adding to our discussions, the report on the I LGBT health forum of V GERES was used as basic material. We believe that professionals working in the health area must observe what causes the sickness of this population, as well as the public policies that facilitate access to SUS.

Keywords: Public Policies. Comprehensive Health Care. LGBT Movement.

\footnotetext{
${ }^{1}$ Mestranda em Curso de Mestrado em Educação Profissional em Saúde - EPSJV/FIOCRUZ. Especialista em saúde Coletiva pela ESPPE-SES/PE. Especialista em Saúde Mental pela UPE. Email: tcsilva@aluno.fiocruz.br

${ }^{2}$ Mestre em Saúde Mental pela UPE. E-mail: e.alexandrefisio@gmail.com

${ }_{3}^{3}$ Especialista em saúde coletiva pela ESPPE-SES/PE.E-mail: jessicasobrinho266@gmail.com

${ }^{4}$ Especialista em saúde Coletiva pela ESPPE-SES/PE. E-mail: ellen.rodriguesı@hotmail.com Especialista em saúde Coletiva pela ESPPE-SES/PE e pelo IBPEX. Email: robertamendesboliveira@gmail.com

${ }^{6}$ Especialista em saúde Coletiva pela ESPPE-SES/PE. E-mail: davi.cicero@hotmail.com
} 


\section{INTRODUÇÃO}

No âmbito da saúde, ao analisar o contexto histórico do Brasil, é possível observar um movimento de mudança de modelo assistencial; do biomédico hospitalocêntrico em direção ao modelo biopsicossocial. Esse cenário de mudança tem como principal alavanca a Reforma Sanitária e a promulgação da Constituição Federal (CF) em I988 (FLEURY, 2009).

A CF 88 instituiu o nosso Sistema Único de Saúde (SUS) e estabeleceu que o Estado deve assegurar ao cidadão o direito à saúde. Essa exigência constitucional ressurge através da promulgação da Lei Orgânica da Saúde (Lei 8.080) e estabelece os princípios norteadores do SUS: universalidade, equidade e integralidade.

A consolidação do SUS pela Lei Orgânica da Saúde configura-se como avanço para inversão do paradigma do modelo de saúde biomédico, centrado na doença e considerando puramente em termos de fatores biológicos. A implementação do Programa de Saúde da Família, em 1994, surge como tentativa de superar as dificuldades decorrentes do modelo biomédico e configura-se como marco histórico da atenção Primária no Brasil (BRASIL, 1997).

No âmbito mundial, o principal marco histórico da atenção primária à saúde é a declaração de Alma-Ata que surgiu a partir da Conferência Internacional sobre Cuidados Primários de Saúde em Alma Ata, na República do Cazaquistão -Antiga República Socialista Soviética- em 1978. Nesse encontro, foram propostos alguns objetivos a serem atingidos pelo setor de saúde em diversos países. Entre os compromissos firmados, destaca-se a centralidade dos cuidados primários em saúde como construção chave para o desenvolvimento humano e social e a responsabilidade dos governos, organizações internacionais e toda a comunidade mundial de prover recursos através de medidas sanitárias e sociais para alcançar esses objetivos (OMS, 1978).

Baseado na Atenção Primária à Saúde, a Estratégia de Saúde da Família alicerça a Política Nacional de Atenção Básica (PNAB), implementada pela portaria 648/GM de 28 de março de 2006. A PNAB estabelece que suas ações devam ser desenvolvidas mais 
próximas a vida das pessoas e deve ser o contato preferencial com usuários, referenciada como principal porta de entrada a toda a rede de atenção à saúde.

A PNAB reafirma o compromisso do SUS com princípios da universalidade, da responsabilização, da humanização, da equidade e da participação social e da integralidade (Brasil, 2006).

Dentro desse contexto, em 2ori, surge a Política Nacional de Saúde Integral de Lésbicas, Gays, Bissexuais, Travestis e Transexuais (PNSI LGBT) se tornando iniciativa para a construção de mais equidade no SUS. O compromisso do Ministério da Saúde com a redução das desigualdades, constitui uma das bases do Programa Mais Saúde - Direito de Todos - lançado em 2008 e que visa à reorientação das políticas de saúde com o objetivo de ampliar o acesso a ações e serviços de qualidade. Por isso, ela contempla ações voltadas para a promoção, prevenção, recuperação e reabilitação da saúde, além do incentivo à produção de conhecimentos e o fortalecimento da representação do segmento nas instâncias de participação popular (BRASIL, 20II).

Quando se abordam questões relacionadas à sexualidade, percebe-se que a mesma é uma constituinte fundamental e imprescindível para a existência de um ser, estando presentes em toda a extensão de sua vida e dos contatos pessoais que nela são desenvolvidos, tanto nas relações interpessoais, aquelas mantidas entre pessoas inseridas em um meio social, como nas relações intrapessoais, e também, sua relação com ele mesmo. O que acaba também por determinar os modos de ser, de se ver, de pensar e de se revelar para a sociedade, pois também vem a ser a sexualidade o principal elemento estruturante da identidade e da personalidade, já que unifica seus níveis biológico, psicológico e social (ABDO; GUARIGLIA-FILHO, 2004).

Podemos ver então que a PNSILGBT tem como marca o reconhecimento dos efeitos da discriminação e exclusão no processo de saúde-doença da população LGBT. Suas diretrizes e seus objetivos estão voltados para mudanças na determinação social da saúde, tendo em vista à redução das desigualdades relacionadas à saúde deste grupo social.

Entendendo também que assim para além de ser mais um dispositivo de enfrentamento a preconceitos e discriminações, esta política e tudo que a circunda, promovem também democracia social, e vêm para ampliar a consciência sanitária tendo 
como caminhos a mobilização no sentido da defesa, do direito à saúde e saúde sexual como componente fundamental para o modelo de promoção da saúde que defendemos e acreditamos.

Objetiva-se socializar uma vivência coletiva de ensino-aprendizagem baseadas em experiências práticas para implementação de uma Política de Saúde em uma regional de saúde do interior de Pernambuco, a partir de olhares e discussões de um programa de residência multiprofissional em Saúde Coletiva que compõem e fortalecem essa rede de saúde.

\section{METODOLOGIA}

O estudo tem como base um relato de experiência, pelo olhar de uma equipe multiprofissional de residentes do programa de residência em saúde coletiva com ênfase em gestão de redes de saúde, da Escola de Saúde Pública de Pernambuco (PRMSC ESPPE). Elaborado e vivenciado dentro do contexto de desenvolvimento das atividades práticas na V Gerência Regional de Saúde do Estado de Pernambuco.

Para elaboração deste trabalho, foi utilizada a descrição da experiência na participação da construção do I fórum de saúde LGBT da V regional de saúde, dentro do processo de ensino - aprendizagem, e de reflexões sobre o "ser" residente e ocupar espaços de protagonismo e participação. O fórum de saúde LGBT aconteceu em 25-04-2018, no município sede da V Regional - Garanhuns - PE. Utilizamos a relatoria do fórum de saúde LGBT como material base para o desenvolvimento deste trabalho.

\section{RESULTADOS E DISCUSSÕES}

Levando em consideração que o desenvolvimento de políticas de saúde para a população LGBT tem história recente no país desde de 2oIr, e com o objetivo de disseminar o conhecimento acerca da Política de Saúde Integral para essa população, o Núcleo de Atenção à Saúde da V GERES, com o apoio dos residentes de Saúde Coletiva da ESPPE, promoveu, o I fórum de saúde LGBT desta regional.

O evento foi direcionado aos profissionais de saúde dos 2I municípios que compõem a V Regional de Saúde, residentes dos programas: Enfermagem Obstétrica; 
Residência Multiprofissional em Atenção Hospitalar com Ênfase em Gestão do Cuidado; Residência Multiprofissional em Saúde Mental; Residência Multiprofissional em Saúde da Família com ênfase em Saúde da População do Campo; Residência Multiprofissional em Saúde Coletiva com ênfase em Gestão de Redes de Saúde e Acadêmicos de Medicina da Universidade de Pernambuco.

Este foi o primeiro fórum na regional trazendo essas discussões e foi registrado as presenças de lideranças e profissionais que já trabalham e dialogam com mais frequência com essa temática. Tendo o evento se dividido em três eixos: o primeiro trazendo diálogos sobre dispositivos de promoção da cidadania, o segundo, meios de fortalecimento para o controle social no SUS e o terceiro, atenção integral: Práticas transformadoras.

Foi observada a importância de ser um fórum voltado para o nível regional, por que pode impulsionar para que os municípios que participaram do evento conheçam a política de saúde LGBT, onde ainda se nota pouco conhecimento sobre a mesma. Sendo Garanhuns - PE, a maior cidade sede desta regional de saúde, as outras cidades são municípios pequenos e ainda percebe-se que pouco ou quase nada se fala sobre a saúde da população LGBT. Por esse pouco conhecimento desta política de saúde, se entende que a participação e adesão no I Fórum, foi moderada, se considerada essa justificativa. Mas o que ficou evidente foi a V GERES, como protagonista para fortalecer parcerias e pactuações para que se assegure a implementação da política no cenário desta regional de saúde.

Ainda é necessário desmistificar questões relacionadas à saúde LGBT e entender a importância de garantir o acesso aos serviços de saúde por esta população. Foi pensando nesta articulação de rede que o evento foi fomentado, e dentro das discussões abordadas, foi trazido em como primeiramente esses espaços de construção de políticas públicas são importantes e que foram a partir de órgãos como o Conselho Estadual de Políticas Públicas para a População LGBT de PE e o Fórum LGBT de PE, que tiveram um papel importante, uma vez que a partir de iniciativas como essas são pautadas as demandas mais recorrentes, a partir do perfil dessa população dentro do estado, e podendo dar voz no que diz respeito ao controle social dentro do SUS, pois estes órgãos participaram e participam da construção no estado e acompanham o desenvolver de cada ação. A partir das demandas 
surgidas, foi visto a necessidade de implantar uma coordenadoria de saúde integral da população LGBT, dentro da Secretaria Estadual de Saúde de Pernambuco, sendo essa uma iniciativa advinda dessa troca e construção social de fortalecimento dos princípios do SUS, sendo o estado de Pernambuco um dos poucos no país a ter esse espaço inovador e exitoso.

Tendo então a coordenadoria de saúde integral da população LGBT desempenhado um papel muito importante, dando esse suporte e fornecendo uma formação qualificada sobre a política, com diálogos intersetoriais também para que no processo de implementação se possa ampliar até outros dispositivos da rede, para além da rede de saúde, dialogando também com a rede de educação e de assistência social por exemplo. $O$ trabalho que vêm sendo feito e que foi abordado no fórum, foi um de formação inicial para os profissionais presentes e apresentação da política nacional de saúde LGBT, explicando termos básicos como: o que significa e a diferença entre orientação sexual e identidade de gênero; entender o porquê de se ter atenção a cada termo; como dialogar com esses indivíduos, enxergando não somente nesta condição e o enquadrando, mas colocando que esses diálogos, eles são pautados na integralidade do usuário como um todo e se trabalhando outras políticas de forma horizontal.

Como por exemplo, se ter um usuário do sexo masculino, negro e gay, como a rede de saúde e principalmente a atenção primária, vai fortalecer esse cuidado, se utilizando das políticas de saúde da população negra, saúde do homem e saúde LGBT, enxergando esse indivíduo e suas potencialidades para além deste enquadramento social, mas tendo esses recortes compreendidos, como necessários, para que se veja esse indivíduo no seu todo, com suas potencialidades e individualidades nesse aspecto, promovendo saúde integral e com equidade.

Não se poderia deixar de mencionar a importância da participação neste evento, dos programas de residência citados acima, uma vez que as residências em saúde são um ponto estratégico de repensar, ajustar e atualizar o processo de formação, tendo estes profissionais inseridos também no serviço como agentes de transformações. Estando esses profissionais se atualizando para repensarem o jeito de fazer saúde e de ser SUS, um jeito novo de articular os serviços e a rede de atenção à saúde. 


\section{CONSIDERAÇÕES FINAIS}

Visto que todas as formas de discriminação, como o caso da LGBTfobia, devem ser consideradas como fatores impulsionadores na produção de doenças e sofrimento. A partir disto, múltiplas são as causas expostas na determinação de adoecimento da população LGBT, necessitando muito claramente de políticas públicas de saúde para essa população.

Sendo o I fórum de saúde LGBT da V GERES - PE, um espaço de fomento a reflexão e o reconhecimento de que se precisa aprofundar mais os estudos e discussões dessa temática, em consequência, do desconhecimento por uma parcela significativa dos profissionais de saúde, o que acarreta em déficits de encaminhamentos e cuidado as especificações da realidade de vida e saúde da população LGBT.

Desta forma foi verificado que estes profissionais de saúde necessitam de maior proximidade com as políticas públicas e com as problemáticas específicas da população LGBT para a qualificação dos serviços prestados pelas diversas áreas.

Sendo assim, os profissionais que atuam na área de saúde, devem estar atentos à reação em cadeia que implica o processo de vulnerabilidade que leva ao adoecimento dessa população, bem como às políticas públicas que facilitam o acesso ao sistema de saúde.

\section{REFERÊNCIAS}

ABDO, C. H. N.; GUARIGLIA FILHO, J. E. F. A mulher e sua sexualidade. São Paulo: Editora Atheneu, 2004. p. 229-268.

BRASIL. Ministério da Saúde (MS). Secretaria de Assistência à Saúde. Coordenação de Saúde da Comunidade. Saúde da Família: uma estratégia para reorientação do modelo assistencial. Brasília: MS;[página na internet] i997. Disponível em: 〈http:// bvsms.saude.gov.br/bvs/publicacoes/cdo9_16.pdf > Acesso em: 02 out. 2018.

- Ministério da saúde. Política Nacional de Atenção Básica. Série E: Legislação

em

Saúde.

Brasília:

MS;

Disponível

em: 
〈http://189.28.128.10o/dab/docs/publicacoes/geral/pnab.pdf 〉 Acesso em: Acesso em: 02 out. 2018.

- Ministério da saúde. Política nacional de saúde integral de Lésbicas, Gays, Bissexuais, Travestis e Transexuais. Brasília: Ministério da Saúde, 2013.

Ministério da saúde. Gabinete do Ministro. Portaria n. 2.836, de or de dezembro de 20II. Institui, no âmbito do Sistema Único de Saúde (SUS), a Política Nacional de Saúde Integral de Lésbicas, Gays, Bissexuais, Travestis e Transexuais (Política Nacional de Saúde Integral LGBT).

. Constituição da República Federativa do Brasil. Brasília: Senado, 1988.

CARDOSO, M. R.; FERRO, L. F. Saúde e População LGBT: Demandas e Especificidades em Questão. Psicologia: ciência e profissão, v. 32, n.3, p.552-563, 2012.

FLEURY, Sonia. Reforma sanitária brasileira: dilemas entre o instituinte e o instituído. Revista Ciência \& Saúde Coletiva, I4(3):743-752, 2009.

LEONY, M. C. (2006). Homofobia, controle social e políticas públicas de atendimento. Pernambuco. Recuperado em 03 abril, 2010, da ADEPOL: http://www.adepolse.org.br/Download/Artigo_homofobia_Publica\%C3\%A 7\% $3 \% \mathrm{C}_{3} \mathrm{~A} 02 \% 5 \mathrm{~B} \%{ }_{5} \mathrm{D}$.doc.

OMS - ORGANIZAÇÃO MUNDIAL DE SAÚDE. Declaração de Alma-Ata. Alma-Ata: OMS, 1978. 3 p. Disponível em: <https://www.opas.org.br/declaracao-de-almaata/ > Acesso em : 02 out. 2018.

PAIVA, V. (2006). Analisando cenas e sexualidades: a promoção da saúde na perspectiva dos direitos humanos. In V. Paiva. Sexualidad, estigma y derechos humanos. Desafios para el acesso a la salud en América Latina. Lima, Peru: FASPA/ UPUCH. 
RAMOS, S., \& CARRARA, S. (2006). A constituição da problemática da violência contra homossexuais: a articulação entre o ativismo e a academia na elaboração de políticas públicas. PHYSIS: Rev. Saúde Coletiva, I6(2), I85-2005.

SOUSA , P. J., ABRAAO, F. M. S., COSTA, A. M. C., \& FERREIRA, L. O.C. F. (2009) Humanização no acolhimento de gays, lésbicas, bissexuais, travestis e transexuais na atenção básica: reflexões bioéticas para enfermagem. In Anais do Segundo Seminário Nacional de diretrizes para enfermagem na atenção básica em saúde, $2^{\circ}$ SENABES. Recife, PE: Associação Brasileira de Enfermagem. Recuperado em is março, 20ı, da ABEN: http://www.abeneventos.com.br/SENABS/cd_anais/pdf/idı4Iro.pdf. 